therefore more cells that are susceptible to infection, as Dr. Minh Dinh, assistant professor in medicine-infectious diseases at Northwestern University in Chicago, Illinois, posited in a recent review of prevailing theories ( $A m J$ Reprod Immunol 2010;65:279-83).

"The virus needs to find a cell to infect," says Dinh. "It has to find target cells."

Another theory is that viruses much prefer the damp area under the foreskin to the dryer surface of an exposed glans. "You have this layer of skin that retracts," says Dinh. "That creates an environment that is dynamic. It is also a warm, moist environment that may allow viral particles to linger longer on the penis, which give the cells there more time to take in the particles."

The foreskin may also have certain structural characteristic relating to its barrier function and permeability that make it more susceptible to viral infection. Whatever the reason, the benefits of circumcision are apparent, says Dinh, while the benefits of the foreskin are anything but.
"There are no health benefits to having foreskin," says Dinh. "Not that I'm aware of." — Roger Collier, CMAJ

\section{CMAJ 2011. DOI:10.1503/cmaj.109-4014}

Editor's note: Second of a six-part series:

\section{Part I: Circumcision indecision:}

The ongoing saga of the world's most popular surgery (www.cmaj.ca /lookup/doi/10.1503/cmaj.109-4021).

\title{
US proposes direct patient access to lab results
}

$\mathrm{P}$ atients in the United States will get their test results directly from clinical labs rather than having to wait for a readout from their doctors, under proposed new American regulations.

The notion is part of the Obama administration's push to empower patients through expanded use of electronic health records, but it is making some doctors nervous.

Kathleen Sebelius, head of the US Department of Health and Human Services, which proposed the rules, predicted the end result would be better medical care as patients get more invested in managing their health. "When it comes to health care, information is power," Sebelius said in a statement (www.hhs.gov/news/press/2011pres /09/20110912a.html). "When patients have their lab results, they are more likely to ask the right questions, make better decisions and receive better care."

Current laws on access to clinical lab results vary from state to state, with just seven states and the District of Columbia expressly allowing test reports to go directly to patients, and seven others allowing direct access only when a patient's doctor approves the release. The reach of the new rules would be huge: affecting 6.1 billion test results annually at nearly 23000 labs.

The American Medical Association and other physician organizations have yet to take a position on the rules, which were open for public comment until Nov. 14. But concern has been expressed about what will be lost if doctors aren't necessarily part of the conversation when lab results are disclosed to patients.

Dr. Mary M. Newman, an internist from Baltimore, Maryland, likes the idea of patients being able to quickly access their own tests, but says some patients may become unduly concerned about minor abnormalities in results or may have to process troubling reports without the support of a doctor. 'I'm

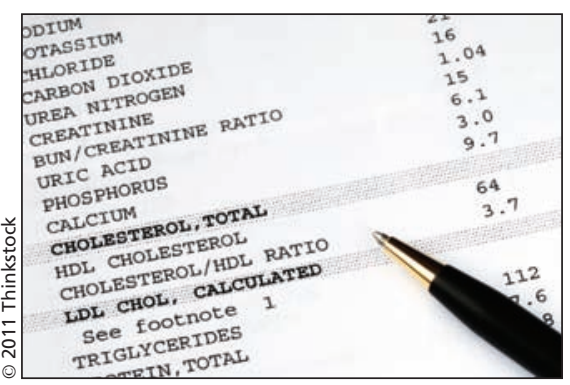

Some physicians are concerned that patients may have trouble processing the information contained in reports.

worried about their anxiety," she says.

Newman would like doctors to have sole access to lab results for 48 or 72 hours before they are released directly to patients, giving doctors time to reach out to patients when warranted. "We know our patients, and so having the news of a problem come from their physician or care team rather than from an unfiltered encounter in the middle of the night, or any time, would be better," she says.

Newman also worries that some patients with serious health problems might get a false sense of reassurance if they receive test results that are normal.
"My bottom line is that it's the patient's information. So they're entitled to it, but what's the best way to get it to them?"

Even proponents of the move express similar concerns.

"Overall, it's a good thing," says Dr. Deborah Peel, founder of the Patient Privacy Rights Foundation, a private watchdog group that advocates for patient control over sensitive health information. "But there are people who are going to get scared when they see things and don't know what it means."

Peel, a Freudian analyst in Austin, Texas, says it's important to couple the direct release of lab results with strong patient education resources so people know how to understand the reports. And she worries that the information also may be more widely distributed once doctors aren't the sole source.

Quest Diagnostics, one of the world's leading lab companies, now releases results to patients (where allowed), via fax or a mobile patient-health app for smartphones. Neil Desai, the firm's executive director for enterprise architecture and technology, says it gives results to doctors 48 hours ahead of patients and doesn't release some types of sensitive results, such as those for HIV and cancer, directly to patients.

As written, the proposed federal rules don't provide for a similar delay or restrict the types of results released to patients. - Nancy Benac, Washington, DC

CMAJ 2011. DOI:10.1503/cmaj.109-4026 